\title{
Pemetaan Masalah Dan Potensi Pengembangan Kawasan Setu Patok Kabupaten Cirebon
}

\author{
${ }^{1}$ Muhfidlatul Qira'ati, ${ }^{2}$ Mira Lestira Hariani, ${ }^{3}$ Nurdiyanto
}

\author{
'Perencanaan Wilayah dan Kota, Universitas Swadaya Gunung Jati, Jawa Barat, Indonesia \\ ${ }^{2,3}$ Teknik Sipil, Universitas Swadaya Gunung Jati, Jawa Barat, Indonesia \\ email: ${ }^{1}$ muhfidlatul.qiraati@gmail.com; ${ }^{2}$ mira.hariani0103@gmail.com; ${ }^{3}$ nurdiantomjl@gmail.com
}

\begin{abstract}
Cirebon Regency has the tourism potential of Setu Patok which should be taken into account as a tourist destination. The Setu Patok area has beautiful views, and the potential for wide green open space as a public open space area. Utilization of this tourism potential needs to be accompanied by efforts to develop villages around the reservoir, one of which is Sinarancang Village. The purpose of the study was to conduct an initial inventory of tourism potential and problems in the Setu Patok area as a development effort. Qualitative descriptive research method is used to present an overview of the area based on data triangulation. The results of the analysis are presented in a map of the potential for regional development. Sinarancang Village has a strategic location because it is close to Setu Patok. The potential for beautiful scenery and the potential for river tourism is the main attraction for Sinarancang Village. This initiation was initiated by building the Kabarong cafe business unit. Kabarong Cafe has an indoor and outdoor concept with beautiful views. BUMDES also develops home industries, namely mortar, brick, and crushed stone. However, the problem is that community participation is still minimal because the mindset they have
\end{abstract} is not a contributive mindset.

Keywords : Tourism Village, Public Open Space, Tourism Development, Potential Mapping, Community Participation

Abstrak. Kabupaten Cirebon memiliki potensi wisata Setu Patok yang patut diperhitungkan sebagai daerah tujuan wisata. Kawasan Setu Patok memiliki pemandangan yang indah, dan potensi ruang terbuka hijau yang luas sebagai kawasan ruang terbuka publik. Pemanfaatan potensi wisata ini perlu dibarengi dengan upaya pengembangan desa-desa di sekitar waduk, salah satunya Desa Sinarancang. Tujuan penelitian adalah untuk melakukan inventarisasi awal potensi dan permasalahan pariwisata di kawasan Setu Patok sebagai upaya pengembangan. Metode penelitian deskriptif kualitatif digunakan untuk menyajikan gambaran wilayah berdasarkan triangulasi data. Hasil analisis disajikan dalam peta potensi pengembangan wilayah. Desa Sinarancang memiliki lokasi yang strategis karena dekat dengan Setu Patok. Potensi pemandangan yang indah dan potensi wisata sungai menjadi daya tarik tersendiri bagi Desa Sinarancang. Inisiasi ini diawali dengan membangun unit usaha kafe Kabarong. Kabarong Cafe memiliki konsep indoor dan outdoor dengan pemandangan yang indah. BUMDes juga mengembangkan industri rumah tangga yaitu mortar, batako, dan batu pecah. Namun yang menjadi permasalahan adalah partisipasi masyarakat masih minim karena pola pikir yang mereka miliki bukanlah pola pikir yang kontributif.

Kata Kunci: Desa Wisata, Ruang Terbuka Publik, Pengembangan Pariwisata, Pemetaan Potensi, Partisipasi Masyarakat

\section{Pendahuluan}

Keberhasilan dari pembangunan nasional ditandai dengan keberhasilan dari pembangunan desa. Partisipasi masyarakat merupakan salah satu indikator dalam mencapai keberhasilan perencanaan pembangunan secara berkelanjutan (Asyiawati, Y. Hindersah, H. Putri 2021).

Partisipasi masyarakat berperan dalam menentukan keberhasilan sebuah pembangunan yang memenuhi kebutuhan seluruh lapisan masyarakat serta 
dirasakan kebermanfaatannya secara berkelanjutan. Kompleksitas indikator pendukung pariwisata berkelanjutan membuat pembangunan tidak hanya difokuskan pada pembangunan infrastruktur fisik umum, tetapi juga pada pembangunan sumber daya manusia. Pembangunan manusia sebagai sumber daya pendukung berperan sangat penting (Budiani et al. 2018). Dalam Undangundang Nomor 6 Tahun 2014 tentang Desa dijelaskan bahwa partisipasi aktif masyarakat dalam proses perencanaan pembangunan bertujuan untuk mewujudkan kesejahteraan masyarakat yang merupakan salah satu perwujudan dari pembangunan berkelanjutan (Asyiawati, Y. Hindersah, H. Putri 2021). Kabupaten Cirebon memiliki potensi wisata Setu Patok yang patut diperhitungkan sebagai salah satu opsi tujuan wisata untuk para wisatawan yang berkunjung ke Cirebon. Salah satu potensi wisata Setu Patok ini berada di Desa Sinarancang Kecamatan Mundu Kabupaten Cirebon. Luas wilayah Desa Sinarancang terdiri atas Pemukiman 35 Ha, Pertanian Sawah 97 Ha, Ladang/ Tegalan $51 \mathrm{Ha}$, Perkantoran 0,72 Ha dan Prasarana Umum Lainnya 0,93 Ha. Jumlah penduduk Desa Sinarancang pada tahun 2020 berjumlah 2.589 jiwa yang terdiri dari 1.309 laki-laki dan 1.280 perempuan. Berdasarkan hasil observasi, Kawasan Setu Patok memiliki pemandangan danau dan potensi ruang terbuka hijau yang lapang sebagai area ruang terbuka publik yang memiliki efek multifungsi dalam aspek sosial, kesehatan, dan ekonomi. Selain pemandangan dan sifat multifungsi tersebut, sebagai bagian dari Kabupaten Cirebon yang memiliki kearifan lokal dan berbagai kisah sejarah, Setu Patok juga memiliki potensi menjadi wahana untuk mengenalkan kearifan lokal Kabupaten Cirebon lebih jauh.

Ruang terbuka hijau masih belum populer atau menjadi tujuan utama untuk masyarakat perkotaan dalam melepas penat atas aktivitas yang sibuk dibandingkan dengan pusat perbelanjaan. Dengan adanya pandemi saat ini, masyarakat terdorong untuk semakin menyadari berharganya berada di luar ruangan, yaitu di alam. Masyarakat pun menyadari pentingnya kawasan hijau sebagai salah satu tujuan alternatif yang efektif untuk menghilangkan masalah kejenuhan dan kebosanan. Mengingat fungsi utama Ruang Terbuka Hijau dalam mendukung kondisi ekologis kota cenderung menurun di kawasan perkotaan, hal itu disebabkan berbagai macam faktor, seperti meningkatnya tingkat polusi. Maka dari itu, Kabupaten Cirebon masih memiliki keistimewaan dengan adanya kawasan Setu Patok yang masih lestari dan potensi wisatanya perlu dikembangkan. Pengembangan pariwisata di Kawasan Setu Patok memerlukan upaya pengembangan desa-desa di sekitar kawasan. Salah satu desa sekitar kawasan tersebut adalah Desa Sinarancang. Di samping berbagai potensi dan peluang wisata yang ada di kawasan Setu Patok, di sana terdapat banyak hal yang masih perlu ditingkatkan dalam rangka memperkenalkan ruang terbuka hijau sebagai wisata alternatif ini secara lebih luas di Kabupaten Cirebon. Salah satu upaya tersebut adalah dengan mengembangkan desa-desa di sekitar Waduk Setu Patok tersebut. Keberadaan Waduk Setu Patok akan memberikan dampak terhadap pengembangan desadesa di sekitar waduk tersebut, baik dari sisi sosioekonomi masyarakat maupun pemanfaatan potensi desanya. Salah satu desa yang ada di sekitar Waduk Setu Patok adalah Desa Sinarancang.

Tujuan penelitian ini adalah melakukan inventarisasi awal terhadap potensi wisata dan permasalahan Kawasan Setu Patok sebagai upaya awal pengembangan. Proses need assessment dan pemetaan potensi menjadi hal penting dalam melakukan perencanaan dan pengembangan pariwisata. Pemetaan dilakukan untuk mengetahui persebaran 
objek wisata yang memiliki daya tarik pariwisata, baik objek wisata yang potensial untuk dikembangkan dengan memperhatikan prinsip pembangunan berkelanjutan maupun yang sudah ada (Budiani et al. 2018). Oleh karena itu, proses need assessment dan pemetaan potensi menjadi penting dilakukan untuk mengetahui potensi dan masalah desa tersebut agar dapat dikembangkan.

\section{Metode Ilmiah}

Penelitian ini memiliki beberapa tahapan. Berikut merupakan tahapan dan metode yang digunakan dalam penelitian.

\section{Teknik Pengumpulan data}

Teknik pengumpulan data yang dibutuhkan meliputi data primer dan data sekunder. Untuk data primer, metode yang dilakukan adalah observasi dan wawancara mendalam kepada berbagai narasumber. Sementara itu, pengumpulan data sekunder dilakukan dengan mengumpulkan dokumen-dokumen penting mengenai perencanaan desa, seperti rencana kerja Desa Sinarancang.

\section{Metode Analisis}

Metode penelitian untuk analisis data yang digunakan dalam pengabdian tentang "Pemetaan Masalah dan Potensi Pengembangan di Kawasan Setu Patok" adalah metode deskriptif kualitatif. Analisis yang dilakukan bertujuan untuk menyajikan gambaran lengkap mengenai suatu kawasan menggunakan data-data yang diperoleh dari hasil wawancara dan observasi partisipatoris sebagai instrumen pengumpulan data. Metode penelitian deskriptif kualitatif adalah metode yang berdasarkan pada filsafat postpositivisme dan digunakan untuk mencari pada kondisi objek yang alamiah (sebagai lawannya adalah eksperimen) peneliti sebagai instrumen kunci utama dalam teknik pengumpulan data yang dilakukan secara trigulasi.

\section{Analisis}

Kemudian, hasil analisis secara kualitatif tersebut diwujudkan atau disajikan ke dalam sebuah peta dasar masalah dan potensi pengembangan kawasan Setu Patok.

Untuk tahapan kegiatan dalam pengabdian kepada masyarakat ini dimulai dari pendahuluan dengan melakukan identifikasi permasalahan, yaitu pemetaan masalah dan potensi kawasan di Desa Sinarancang, Kecamatan Mundu, Kabupaten Cirebon. Kegiatan selanjutnya merupakan tahap pengumpulan data dan survei lokasi. Pada tahap pengumpulan data diperlukan data primer dan data sekunder. Untuk data primer didapat dari kegiatan survei lokasi, wawancara, dan kegiatan identifikasi masalah dan potensi. Untuk data sekunder yang diperlukan adalah Rencana Tata Ruang Wilayah Kabupaten Cirebon, Kabupaten Crebon dalam Angka Tahun 2020, Kecamatan Mundu dalam Angka Tahun 2020, Peta Kabupaten Cirebon, Citra Satelit Kawasan Setu Patok, dan Data Potensi Desa.

Tahapan selanjutnya adalah pembuatan peta dasar kawasan Setu Patok dengan menggunakan metode interpretasi dan digitalisasi citra satelit kemudian dilanjutkan dengan proses analisis. Adapun analisis yang dilakukan adalah analisis permasalahan dan potensi pengembangan kawasan. Tahap terakhir adalah memetakan hasil analisis permasalahan dan potensi pengembangan ke dalam peta dasar kawasan sehingga menghasilkan produk berupa peta masalah dan potensi pengembangan kawasan Setu Patok.

\section{Hasil dan Pembahasan}

Dalam rangka mengetahui kondisi awal mitra Pengabdian Kepada Masyarakat (PKM) yang menjadi objek PKM dilakukan terlebih dahulu studi lapangan pendahuluan. Studi pendahuluan ini dilakukan dengan 
melakukan pengamatan langsung ke Desa Sinarancang, wawancara, dan juga mempelajari dokumen yang berkaitan. Desa Sinarancang merupakan salah satu dari 12 Desa di Kecamatan Mundu. Desa lain di Kecamatan Mundu adalah Desa Bandengan, Banjarwangunan, Citemu, Luwung, Mundumesigit, Mundupesisir, Pamengkang, Penpen, Setupatok, Sinarancang, Suci, dan Waruduwur. Letak geografis Desa Sinarancang sebagai berikut (Profil Desa Sinarancang, 2021):

Sebelah Utara: Desa Setupatok

Sebelah Barat: Kelurahan Argasunya

Sebelah Selatan: Desa Nanggela

Sebelah Timur: Desa Penpen

Sebagian besar masyarakat di sana bermata pencaharian sebagai buruh, pedagang, dan petani. Kawasan Setu Patok tidak hanya memiliki pemandangan yang indah untuk dilihat, tetapi potensi ruang terbuka hijau yang lapang sebagai area ruang terbuka publik memiliki efek multifungsi dalam aspek sosial, kesehatan, dan ekonomi.

\section{Analisis Pemetaan Potensi Pengembangan Kawasan Setu Patok, Desa Sinarancang.}

Desa Sinarancang memiliki lokasi yang strategis karena berdekatan dengan Setu Patok. Potensi pemandangan yang indah menjadi daya tarik tersendiri bagi Desa Sinarancang sehingga menjadi salah satu motivasi BUMDES Desa Sinarancang untuk mengembangkan potensi desa wisata. Inisiasi ini dimulai dengan membangun unit usaha di lokasi yang memiliki nuansa pemandangan Setu Patok, yaitu Kafe Kabarong. Unit usaha ini memiliki beberapa bertujuan, yakni selain untuk menarik para pengunjung Setu Patok mengunjungi Desa Sinarancang, juga untuk menggerakkan ekonomi desa agar dapat berkontribusi pada Pendapatan Asli Daerah dan juga dapat menyejahterakan masyarakat. Kafe Kabarong ini dapat bermanfaat sebagai ruang publik yang memiliki konsep kafe indoor dan outdoor dengan pemandangan indah dari Setu Patok serta udara yang segar dari kawasan hijau sekitarnya berupa kawasan pertanian dan perkebunan. Selain potensi wisata alam yang dimiliki, Desa Sinarancang pun melalui inisasi BUMDES hendak mengembangkan home industry yang ada di desa. Home industry yang terkenal di desa ini adalah home industry cobek. Beberapa masyarakat sekitar memiliki mata pencaharian sebagai pengrajin cobek. Penjualan dan pemasaran dilakukan hingga ke luar kota. Selain cobek, terdapat pula home industry Batu Bata dan Batu Split.

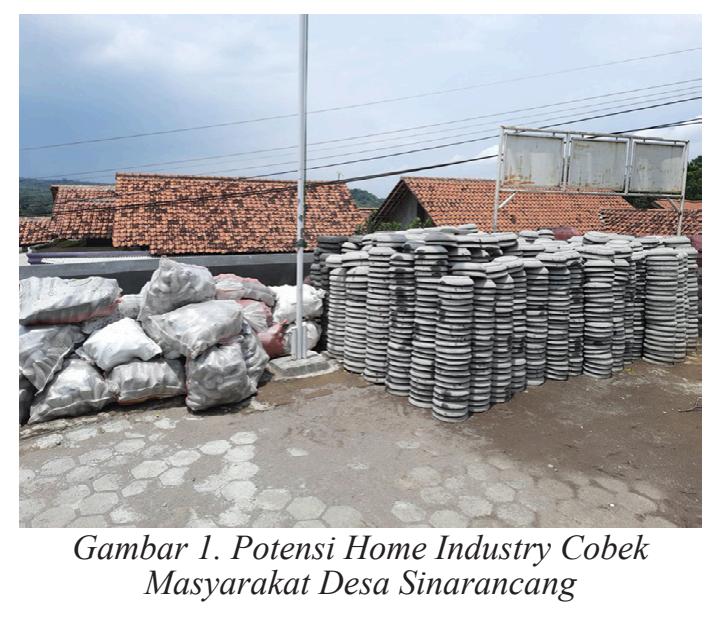

Potensi wisata lain yang akan dikembangkan adalah potensi wisata sungai berupa arung jeram.

Desa Sinarancang pun memiliki hasil pertanian dan perkebunan yang masih mendominasi mata pencaharian masyarakatnya. Potensi perkebunan tersebut adalah singkong, pisang, cabai, bawang, buah-buahan, kentang, dan kacang. Selain perkebunan dan pertanian, Desa Sinarancang pun memiliki potensi peternakan kerbau.

Selain dari potensi wisata alam, Desa Sinarancang pun memiliki masyarakat yang aktif membuat variasi produk-produk home industry. Penjualan dan pemasaran produk-produk tersebut menjadi ciri khas yang menandai keunikan dan kearifan lokal Desa Sinarancang sebagai kawasan Setu Patok 
yang merupakan bagian dari Kabupaten Cirebon. Hal ini dapat menjadi potensi pengembangan desa wisata ke depannya karena dapat mengoptimalkan fungsi dan peran dari ruang terbuka publik dan ruang terbuka hijau melalui adanya kunjungan masyarakat, baik yang berasal dari dalam maupun dari luar Kota Cirebon.

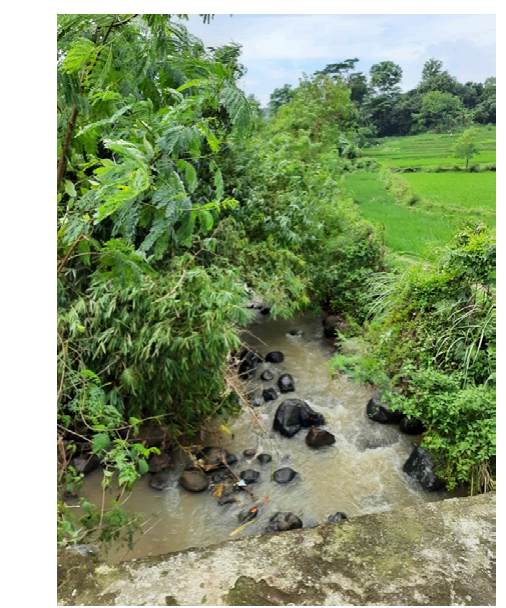

Gambar 2. Potensi Wisata Sungai, Arung Jeram, Desa Sinarancang

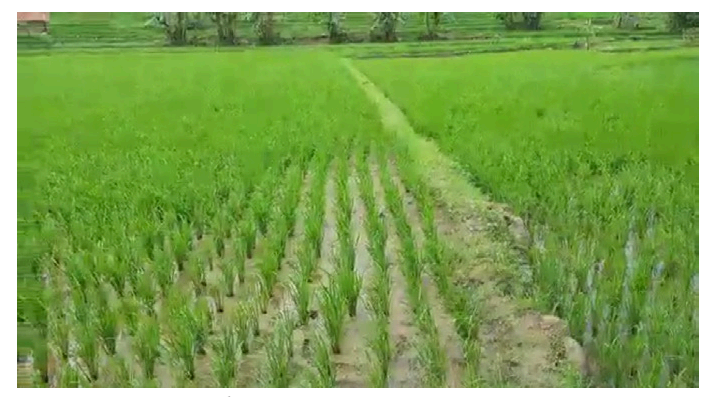

Gambar 3. Potensi Pertanian Desa Sinarancang

Harapannya, pengembangan desa wisata ini dapat memberikan banyak keuntungan, seperti meningkatnya pendapatan tambahan (additional income) untuk masyarakat yang tinggal di sekitar lokasi daya tarik wisata, tersedianya lapangan kerja, mendorong penguatan ekonomi lokal, sekaligus dapat meningkatkan Pendapatan Asli Daerah (PAD), serta berkembangnya seni budaya lokal (Sugiarti, Rara 2016). Oleh karena itu, melalui pemetaan potensi Desa Sinarancang sebagai kawasan Setu Patok diharapkan dapat menjadi awal pengembangan sebagai Desa Wisata yang dapat memenuhi kebutuhan masyarakat yang akan berdampak pada kesejahteraan masyarakat dan mendorong Pendapatan Asli Daerah. Berikut merupakan pemetaan potensi Kawasan Setu Patok.

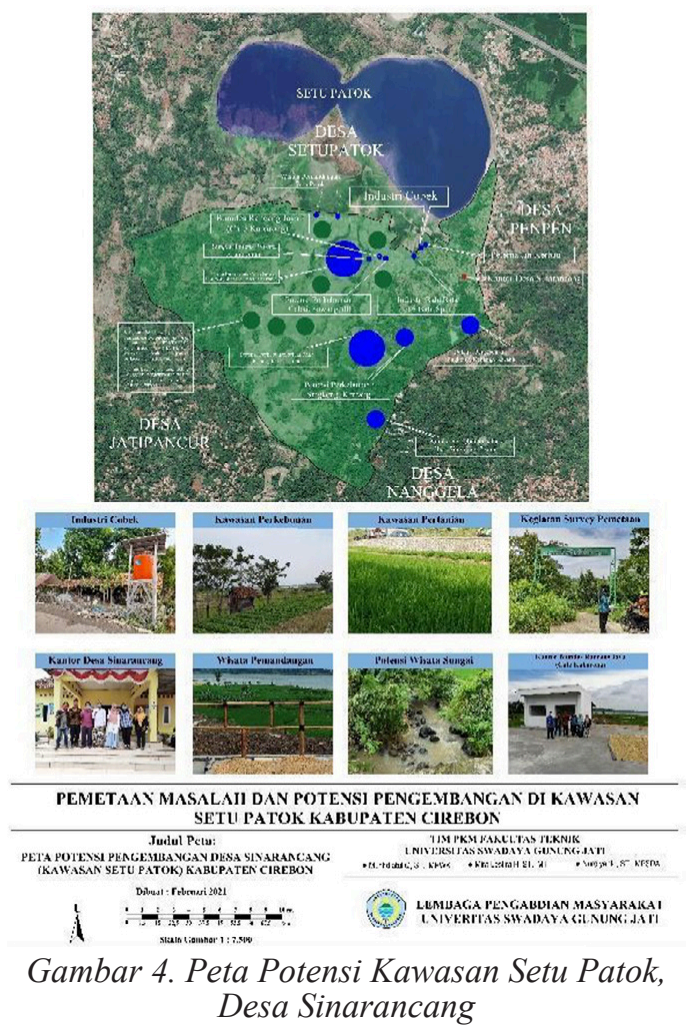

\section{Analisis Permasalahan Kawasan Setu Patok, Desa Sinarancang.}

Secara umum, desa dapat menggambarkan mengenai keadaan sumber daya fisik (alam dan buatan) yang bertujuan untuk: Memahami akan jenis, jumlah, dan sumber daya di desa; Sebagai alat untuk menggali/menjaring masalah yang ada di tingkat dusun terutama yang berkaitan dengan pemenuhan atas hak dasar (permasalahan pengembangan wilayah, sosial, budaya, dan ekonomi); Sebagai alat untuk menggali potensi yang ada di tingkat Dusun, Rukun Warga, dan Rukun Tetangga; Menyamakan persepsi tentang masalah dan potensi yang ada di tingkat Dusun, Rukun Warga, dan Rukun Tetangga.

Di samping itu, dalam
pengembangan Desa


terdapat permasalahan yang dapat muncul dan perlu ditangani. Keterlibatan masyarakat masih perlu ditingkatkan. Keterlibatan tersebut meliputi rasa memiliki untuk membangun inisiasi unit usaha yang nantinya akan memberikan dampak bagi seluruh masyarakat desa bukan saja menjadi tugas dari para pemerintah desa, melainkan juga dari seluruh lapisan masyarakat. Salah satu kelemahan dalam mewujudkan pembangunan secara berkelanjutan adalah kurangnya peran masyarakat dalam memberikan kontribusi terhadap pembangunan (Asyiawati, Y. Hindersah, H. Putri 2021). Sesuatu yang menjadi penting dalam mewujudkan pembangunan desa secara berkelanjutan adalah dengan partisipasi masyarakat sehingga perencanaan pembangunan tersebut dapat dirasakan oleh semua lapisan masyarakat, sebagaimana dijelaskan dalam (Undang-Undang RI No. 6 2014).

Kondisi masyarakat Desa Sinarancang memang masih minim dalam partisipasi pembangunan desa. Masyarakat masih memiliki pola pikir bahwa bantuan adalah yang diperoleh secara langsung atau tunai daridesa; belum bisa berpikir bagaimana berkontribusi terhadap pembangunan desa (Sairoh, Sekretaris Desa Sinarancang, 2021).

\section{Berdasarkan karakteristik} sosial masyarakat di sini, keterlibatan masyarakatnya masih minim. Dalam inisiasi pengerjaan proyekawalBUMDES ini, kita sudah mulai melibatkan masyarakat dalam pembangunan Kafe Kabarong sebagai salah satu unit desa wisata Sinarancang dengan menggunakan jasa dan sumber daya manusia di dalam masyarakat dalam proyek pembangunan ini walaupun memang akhirnya agak lama dan sulit untuk diajak cepat. (Halim, Ketua BUMDES, 2021).

Dalam rencana pembangunan Desa Sinarancang sebagai desa wisata yang dimulai dengan inisiasi Kafe Kabarong, masyarakat mulai dilibatkan, baik sebagai penyedia bahan bangunan maupun jasa pembangunan. Selain itu, sosialisasi pembangunan Kafe Kabarong pun dilakukan pada masyarakat juga pada kepala desa dari desa-desa sekitar Desa Sinarancang.

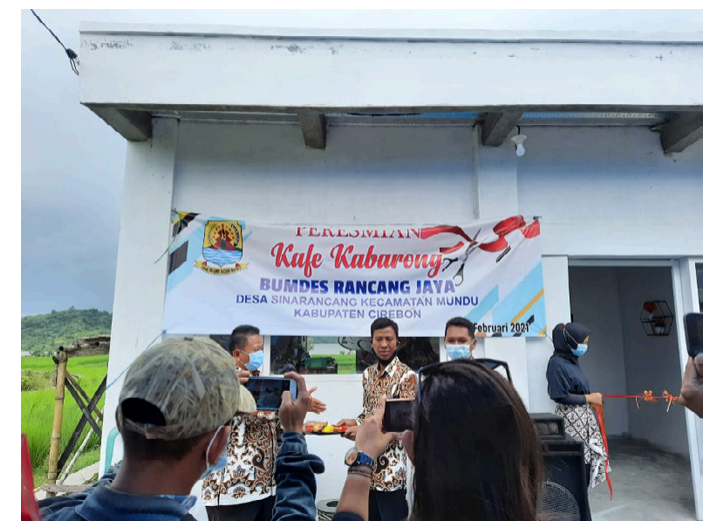

Gambar 5. Launching Kafe Kabarong, BUMDES Rancang Jaya, Desa Sinarancang

Partisipasi masyarakat memegang peranan penting dalam proses perencanaan pembangunan agar lebih terarah sesuai dengan kebutuhan masyarakat dalam rangka mendorong pembangunan. Hal ini dilakukan karena melalui partisipasi masyarakat dapat diperoleh informasi mengenai kebutuhan masyarakat desa serta masyarakat akan menjalankan dan menghargai dari pembangunan desa apabila diikutsertakan dalam proses perencanaan pembangunan yang dilakukan. Hal ini merupakan hak demokratis dari masyarakat dalam proses perencanaan pembangunan desa. (Rahman 2016).

Silkhondze (1999) menegaskan bahwa pendekatan pengembangan masyarakat berorientasi pada kebutuhan masyarakat (Pratama, 2019). Apabila keterlibatan masyarakat Desa Sinarancang masih minim, pembangunan desa akan kurang dalam memenuhi kebutuhan masyarakat sehingga juga akan berdampak pada kesejahteraan yang dapat dirasakan langsung oleh masyarakat. Oleh karena itu, perlu adanya upaya peningkatan tingkat partisipasi masyarakat melalui indikatorindikator tingkat partisipasi masyarakat. 
Tingkat partisipasi masyarakat sebagaimana yang dikemukakan oleh Arnstein (1969) dalam (Wirawan 2015) mencakup delapan tingkatan, yaitu (1) manipulation (manipulasi), (2) theraphy (terapi/penyembuhan), (3) informing (informasi), (4) consultation (konsultasi), (5) placation (penentraman/perujukan), (6) partnership (kerja sama), (7) delegated power (pelimpahan kekuasaan), dan (8) citizen control (kontrol masyarakat).

Upaya peningkatan tingkat partisipasi masyarakat dilakukan untuk mencapai keberhasilan dalam pemberdayaan masyarakat yaitu kesejahteraan, kesadaran kritis, akses, partisipasi, dan kendali. UNICEF mengusulkan lima dimensi sebagai tolok ukur untuk mencapai keberhasilan pemberdayaan masyarakat, di antaranya adalah kesejahteraan, akses, kesadaran kritis, partisipasi, dan kendali. Kelima dimensi tersebut merupakan kategori analisis dinamis, saling terkait secara sinergis, saling menguatkan, dan saling melengkapi satu sama lain (Nugraha., Aviasti. Mulyati, Shofi Dewi. Amaranti 2021).

\section{Kesimpulan dan Saran}

Berdasarkan kajian dan pengabdian masyarakat yang dilakukan, sebagaimana dengan tujuan pengabdian ini adalah melakukan inventarisasi awal terhadap potensi wisata dan permasalahan Kawasan Setu Patok sebagai upaya awal pengembangan pariwisata. Kawasan Desa Sinarancang memiliki potensi wisata alam berupa pemandangan, wisata sungai, potensi ruang terbuka publik, potensi home industry, potensi ruang terbuka hijau, potensi kawasan pertanian, peternakan dan perkebunan. Penjualan dan pemasaran produk-produk tersebut menjadi ciri khas yang menandai keunikan dan kearifan lokal Desa Sinarancang sebagai kawasan Setu Patok yang merupakan bagian dari Kabupaten Cirebon. Hal ini dapat menjadi potensi pengembangan desa wisata ke depan karena dapat mengoptimalkan fungsi dan peran dari ruang terbuka publik dan ruang terbuka hijau melalui adanya kunjungan masyarakat yang akan berwisata, baik yang berasal dari dalam maupun dari luar Kabupaten Cirebon.

Sementara itu, permasalahan Desa Sinarancang adalah keterlibatan dan partisipasi masyarakat yang masih minim dalam pembangunan desa karena pola pikir yang dimiliki. Menurut pemerintah desa, masyarakat masih memiliki pola pikir sebagai penerima bukan sebagai inisiator. Mereka masih berpikir memperoleh bantuan secara langsung. Masyarakat perlu memperoleh edukasi agar memiliki pola pikir inisiator, yaitu kontributif terhadap pembangunan desa. Beberapa hal yang dapat dilakukan demi meningkatkan partisipasi adalah melalui peningkatan indikator tingkat partisipasi masyarakat, yaitu salah satunya adalah meningkatkan intensitas pertukaran informasi dan konsultasi serta pembentukan kerja sama. Upaya peningkatan tingkat partisipasi masyarakat dilakukan untuk mencapai keberhasilan pemberdayaan masyarakat melalui kesejahteraan, akses, kesadaran kritis, partisipasi, dan kendali.

\section{DAFTAR PUSTAKA}

Asyiawati, Y. Hindersah, H. Putri, Y. Y. 2021. "Identifikasi Partisipasi Masyarakat Dalam Mewujudkan Pembangunan Desa Berkelanjutan (Studi Kasus: Desa Ketapang Indah-Kecamatan Singkil Utara)." Ethos 9(1):63-71.

Budiani, Sri Rahayu, Windarti Wahdaningrum, Dellamanda Yosky, Eline Kensari, Hendra S. Pratama, Henny Mulandari, Heru Taufiq Nur Iskandar, Mica Alphabettika, Novela Maharani, Rizka Fitria Febriani, and Yanti Kusmiati. 2018. "Analisis Potensi 
Dan Strategi Pengembangan Pariwisata Berkelanjutan Berbasis Komunitas Di Desa Sembungan, Wonosobo, Jawa Tengah.” Majalah Geografi Indonesia 32(2):170.

Nugraha., Aviasti. Mulyati, Shofi Dewi. Amaranti, Reni. 2021. "PROGRAM PEMBERDAYAAN POTENSI MASYARAKAT DI DESA BOJONG KABUPATEN NAGREK." Ethos 9(1):23-29.

Pratama, Dinar. 2019. "Gerakan Desa Sadar Wisata: Pengabdian Pada Masyarakat Desa Penyak Kabupaten Bangka Tengah.” Jurnal Pengabdian Masyarakat 3(1):49-74.

Rahman, Khairul. 2016. "Pemberdayaan Partisipasi Masyarakat Dalam Pembangunan Desa." WEDANA Jurnal Pemerintahan, Politik Dan Birokrasi 2(1):189-99.

Sugiarti, Rara, Dkk. 2016. "Pengembangan Potensi Desa Wisata Di Kabupaten Ngawi." Cakra Wisata 17(2):14-26.

Undang-Undang RI No. 6, 2014. 2014. UNDANG-UNDANGREPUBLIK INDONESIA NOMOR 6 TAHUN 2014 TENTANG DESA.

Wirawan, Ricky. Mardiyono. Nurpratiwi Ratih. 2015. "PARTISIPASI MASYARAKAT DALAM PERENCANAAN PEMBANGUNAN DAERAH." Ilmu Sosial Dan Ilmu Politik 4(2):301-12. 